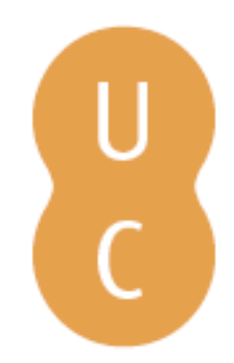

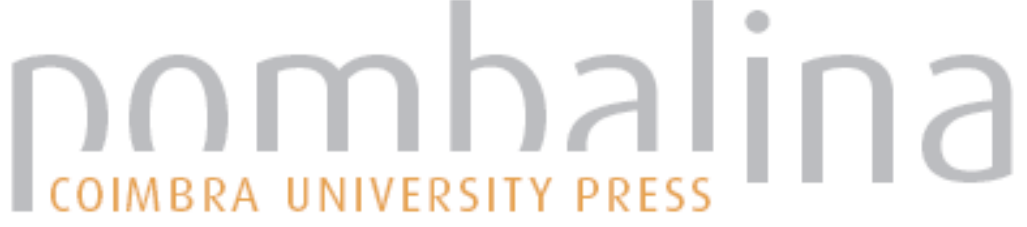

\section{Los Estados en el orden internacional contemporáneo}

Autor(es): Remiro Brotóns, Antonio

Publicado por: Imprensa da Universidade de Coimbra

URL

persistente: URI:http://hdl.handle.net/10316.2/47425

DOI: $\quad$ DOI:https://doi.org/10.14195/978-989-26-1524-0_1

Accessed : $\quad$ 26-Apr-2023 13:47:59

A navegação consulta e descarregamento dos títulos inseridos nas Bibliotecas Digitais UC Digitalis, UC Pombalina e UC Impactum, pressupõem a aceitação plena e sem reservas dos Termos e Condições de Uso destas Bibliotecas Digitais, disponíveis em https://digitalis.uc.pt/pt-pt/termos.

Conforme exposto nos referidos Termos e Condições de Uso, o descarregamento de títulos de acesso restrito requer uma licença válida de autorização devendo o utilizador aceder ao(s) documento(s) a partir de um endereço de IP da instituição detentora da supramencionada licença.

Ao utilizador é apenas permitido o descarregamento para uso pessoal, pelo que o emprego do(s) título(s) descarregado(s) para outro fim, designadamente comercial, carece de autorização do respetivo autor ou editor da obra.

Na medida em que todas as obras da UC Digitalis se encontram protegidas pelo Código do Direito de Autor e Direitos Conexos e demais legislação aplicável, toda a cópia, parcial ou total, deste documento, nos casos em que é legalmente admitida, deverá conter ou fazer-se acompanhar por este aviso.

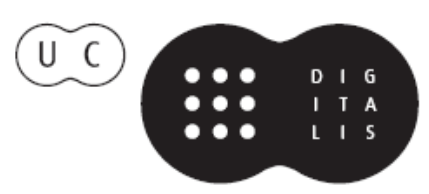


JOSÉ MANUEL PUREZA JOSÉ JUSTE RUIZ (COORDS.)
IMPRENSA DA

UNIVERSIDADE

DE COIMBRA

COIMBRA

UNIVERSITY

PRESS
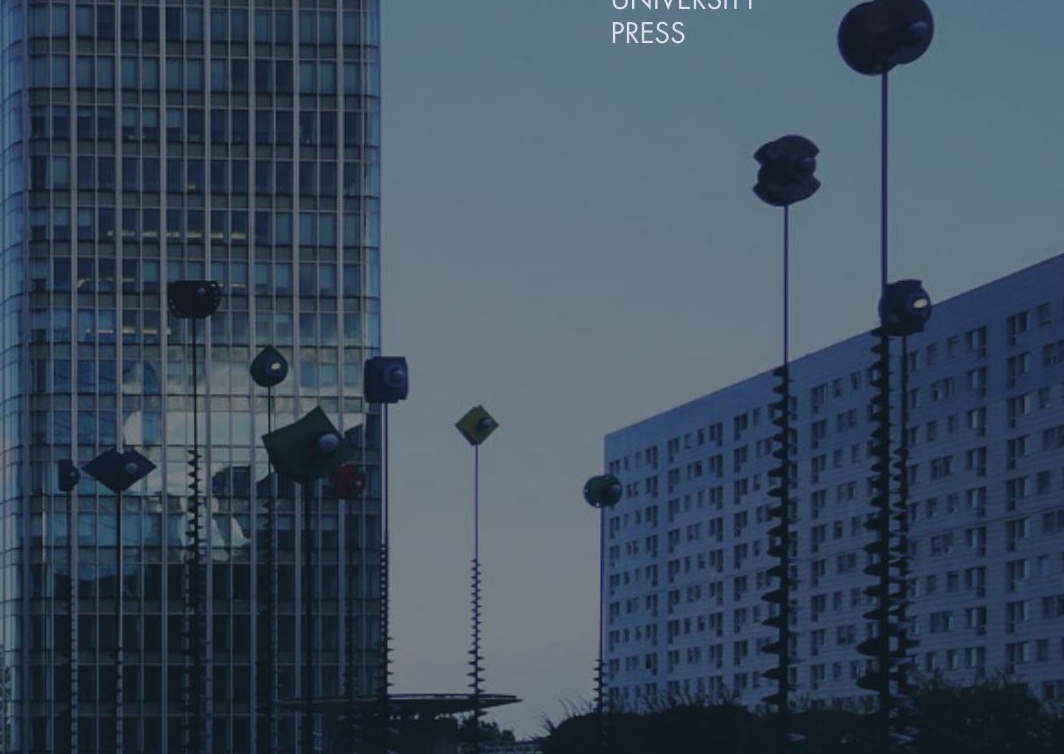

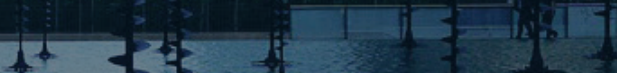

OS ESTADOS

EA ORDEM

INTERNACIONAL

CONTEMPORANEA

ATAS DO V ENCONTRO LUSO-ESPANHOL DE Professores de Direito internacional e RELAÇÕES INTERNACIONAIS 


\section{LOS ESTADOS EN EL ORDEN INTERNACIONAL CONTEMPORÁ N E O}

\section{Antonio Remiro Brotóns}

1. El Estado es, primero, una realidad histórica y, luego, un concepto jurídico. Definido como el sujeto primario y plenario del Derecho Internacional, ha sido una y otra vez discutido tanto como deseado en ambos planos, el histórico y el legal. Baste recordar la aventura del Estado revolucionario acuñado y acunado por el marxismo-leninismo como instrumento de la destrucción del propio Estado y transformado en gran potencia competidora de los grandes Estados capitalistas. Al fin del día el Estado revolucionario si acabó con algo fue consigo mismo. O, en otro orden de cosas, tengamos presente el largo centenar de Estados nuevos surgidos de la descolonización en la segunda mitad del siglo XX, un proceso hoy absolutamente residual. Estos dos hechos sirvieron, por otro lado, para articular esa cruz (Este-Oeste/Norte-Sur) que nos ha permitido durante esos cincuenta años de la pasada centuria explicar -y, sobre todo, evaluar- las relaciones y el orden internacional en términos de seguridad y desarrollo. En el Derecho Internacional los reflejos han sido múltiples y variados, desde las reglas sobre la sucesión de Estados a la ilusión, fallida como un cohete que explosiona antes de entrar en órbita, del Nuevo Orden Económico Internacional, basado en la soberanía de los recursos naturales y la desigualdad compensadora en beneficio de los más débiles. 
2. No deja de ser paradójico que al mismo tiempo que se critica al Estado como una forma de organización política de los grupos humanos incapaz de satisfacer en la era de la globalización los intereses de la pretendida comunidad internacional que forman todos ellos, proliferen los movimientos nacionalistas separatistas dispuestos a alumbrar Estados nuevos en cuadrículas de Estados existentes o a resucitar, trayéndolos de las profundidades de una historia a menudo inventada, Estados tan ancestrales, que hasta llamarlos Estados resulta anacrónico.

Obviamente, la descomposición del llamado, con una cierta dosis de humor negro, socialismo real, contribuyó a ello a partir de la última década del siglo $\mathrm{XX}$, y lo hizo de manera muy perturbadora, pues permitió presentar como demócratas a quienes hacían del nacionalismo el ariete de su lucha contra los regímenes comunistas que habían amamantado a muchos de sus dirigentes, ese nacionalismo que, con el Secretario del PCUS a la cabeza en 1956, habían declarado muerto y sepultado gracias a la implantación del marxismo-leninismo. Menudo chasco. El efecto llamada no se limitó a los Estados bajo dictaduras de variado pelaje, eventualmente en tránsito a la democracia, sino que vino para quedarse como nociva epidemia en Estados democráticos con nacionalismos más o menos durmientes y/o bien alimentados, donde declararse socialista y nacionalista es una antinomia que se vive sin rubor.

3. Por otro lado, cuando se habla de la crisis del Estado soberano conviene matizar, porque son muchos los Estados soberanos que gozan de buena salud y seguramente la crisis va por barrios. Acabamos de mencionar el primero de ellos, en el que la crisis procede de la desagregación del Estado, como consecuencia de la energía centrífuga de los movimientos separatistas, tanto más peligrosos cuando sus representantes ocupan las instituciones locales que el Estado -un Estado desorientado ante su propio destino- creó 
justamente para saciar su voracidad. La crisis nace, en otros casos, de la amenaza de la confiscación de la soberanía por diferentes tribus, trátese de movimientos terroristas, narcotraficantes o marcas de crimen organizado en Estados fallidos, vulnerables o que se dicen revolucionarios como, en otro plano, de las plantillas salvajes neoliberales al servicio de poderes fácticos transnacionales que desprecian los intereses generales de una ciudadanía contemplada como una masa domesticada de siervos consumidores; su modelo de Estado es el minimalista, guardia de la porra, garante del libre mercado y gestor de beneficencia.

4. Ese es, probablemente, el quid de la cuestión cuando uno se plantea en términos concretos su opinión sobre el Estado como concepto y como singular realidad histórica. El Estado se legitima por la libre determinación de una población. Este principio y el principio democrático son uno y el mismo y es justamente la calificación como democrático del Estado la que en el orden internacional contemporáneo permite poner al servicio de su integridad los demás principios fundamentales del Derecho Internacional. La responsabilidad de proteger a las personas presentes en su territorio comienza en el Estado local y la soberanía y no intervención en sus asuntos se justifica por su condición democrática. A partir de ahí, las nociones de pueblo o nación se reconducen al Estado mismo. El pueblo y la nación se identifican con la población ciudadana. Ciertamente, el Estado democrático, respondiendo a otro principio fundamental, el de autoorganización, puede verse a sí mismo, constitucionalmente, como el fruto de un contrato entre diferentes pueblos y naciones. Eso es también reflejo de su soberanía. Pero no cabe desde el exterior combatir en términos jurídicos la conservación del Estado dado cuando éste es un Estado democrático. No hay en este orden pueblos o naciones con un derecho natural a adquirir la condición de Estados soberanos, aunque en su seno las 
libertades y derechos que les son reconocidos les han de permitir defender pacíficamente su causa.

Identificar un pueblo o nación no es, por otro lado, una tarea fácil. ¿Depende de un criterio étnico, religioso, lingüístico, cultural, histórico? ¿Es una cuestión personal, de autoelección? ¿Tiene una base territorial? Seguramente de todo un poco; pero parece razonable afirmar que los nacional-separatistas de pata negra sorben energía en una identidad étnica y/o cultural en sentido amplio, asentada en un territorio histórico, atrayendo a la población inmigrante y a sus criaturas mediante una oferta de autoidentificación. Sostener el separatismo sobre la base de los valores que llamamos 'republicanos' sería absurdo, pues ya son propios del Estado democrático, con independencia de su forma de gobierno.

5. Naturalmente, en todo este vaivén no pueden faltar los símbolos, banderas, himnos, escudos, leyendas o denominaciones, amados unos con tanto fervor como detestados otros con el mayor de los desprecios. No se trata de un hecho meramente folclórico. Hay Estados que han cambiado de nombre para subrayar raíces históricas o identitarias y otros que tratan de negarles el derecho a hacerlo. Siam pasó a ser Tailandia, Ceilán Sri Lanka y Birmania, Myanmar, pero el deseo de la antigua República Yugoslava de Macedonia de llamarse República de Macedonia tout court ha chocado con la persistente oposición de Grecia en las organizaciones internacionales, como si fuera titular de una marca registrada. ¿Qué decir de Kosovo? El desideratum de los albaneses que dominan demográfica y políticamente este histórico territorio serbio ha sido siempre la unión con Albania, justamente lo que fue prohibido por los patrocinadores de su miserable independencia. No es la insípida y sobrevenida bandera kosovar la que animaba las manifestaciones independentistas cuando Kosovo era una provincia autónoma de Serbia, diez años bajo la administración de las Naciones Unidas, 
sino la roja con el águila bicéfala de Albania, junto, desde luego, con la de Estados Unidos, el gran patrón del nuevo Estado. Todo un desagravio, teniendo en cuenta en cuantos lugares la bandera de las barras y estrellas ha sido pasto de las llamas.

La bandera de la Unión Europea, permítaseme el excursus, ni siquiera ha dado para eso. Aparece en los lugares públicos de los países miembros -y no en todos- como un jarrón chino, pero los enemigos de la Unión se han esforzado por eliminarla, como cualesquiera otros símbolos, de los tratados constitutivos; bien es cierto que el rumbo del proyecto europeo es tan neoliberal e insolidario que el escepticismo puede nutrirse no sólo de nacionalistas sino de genuinos europeístas, avergonzados hoy por la respuesta mezquina de la Unión y de sus miembros ante los desplazamientos de quienes huyen de guerras de las que somos corresponsables. Y aún sobre banderas. La Bolivia actual, que ha dado visibilidad y presencia política a los pueblos indígenas, ha querido reforzar el símbolo de su plurinacionalidad, recogida ya en su denominación constitucional, adoptando junto a su bandera tradicional, una segunda bandera multicolor. En Venezuela el comandante Chávez quiso significar su aliento revolucionario calificando constitucionalmente la República como bolivariana. Y añadió una estrella, la octava, a las que se dibujan en la azul franja central horizontal de su bandera tricolor, también roja y gualda.

6. Pero esta última estrella ya no tenía que ver con la ideología, sino con el guiño a una reivindicación secular de Venezuela, la del territorio al oeste del río Esequibo, ocupado por la República Cooperativa de Guyana, heredera de la rapacidad colonial del Reino Unido que andaba buscando las bocas del Orinoco frente a una Venezuela heredera de títulos españoles que apenas podía defender frente al imperio británico. Es este un contencioso territorial clásico, tan interesante como mal conocido, en el que ahora no me puedo 
detener. Diré, tan sólo, que tres meses antes de que se consumara la independencia de Guyana, en 1966, Venezuela, Reino Unido -y la emergente Guyana- suscribieron en Ginebra un Acuerdo para solucionar la diferencia originada por la afirmación venezolana de que la sentencia arbitral de 1899 que había reconocido a Reino Unido como soberano sobre el territorio en disputa era nula como consecuencia de un proceso viciado por la corrupción política y el desdén imperial a la igualdad soberana de los Estados. Se trataba, ahora, de alcanzar un arreglo "práctico" satisfactorio para ambas Partes mediante el recurso sucesivo a los diferentes medios de solución pacífica de diferencias y el esfuerzo debía continuarse hasta lograr el acuerdo. Han pasado cincuenta años sin que las posiciones se hayan movido, siendo baldío el esfuerzo, tal vez no demasiado insistente, de quienes han desempeñado buenos oficios por designación del Secretario General de las Naciones Unidas. El aparente descubrimiento de gas y petróleo en la plataforma continental en que se proyecta la costa del territorio en litigio añade hoy urgencia a una solución; más aún cuando detrás de Guyana se advierte la sombra de las grandes empresas norteamericanas del sector y, también, del departamento de Estado, atento a hurgar en la actual vulnerabilidad del régimen chavista.

Esta lucha por los recursos marinos y el dominio estratégico adquiere especial virulencia hoy en el mar del sur de la China donde la República Popular, consciente de su superioridad sobre los vecinos, está ejecutando una política de ocupación de rocas a las que califica como islas y de bajíos que transforma en rocas que, debidamente engarzadas mediante obras públicas, se convierten en islas portuarias y aeroportuarias, con presencia aeronaval permanente, aval de sus pretendidos títulos históricos. Dame un bajío y haré de él una roca; dame una roca y la transformaré en isla; dame un racimo de islas, rocas y bajíos y te regalaré un archipiélago. Seguramente hay un proverbio chino detrás. Para China no hay ar- 
bitraje que valga. El mar que lleva su nombre le pertenece porque así lo ha decidido unilateralmente y ocupa. Filipinas, Malasia y, en menor medida, Vietnam, miran a los Estados Unidos que, de vez en cuando, pasean su bandera por aquellos espacios, evitando una confrontación que podría afectar intereses financieros.

También huele a mar el contencioso sobre el acceso soberano de Bolivia al océano Pacífico que Chile se comprometió a negociar reiteradamente una vez que en 1904 consiguió formalizar la cesión del extenso departamento Litoral boliviano que el Ejército chileno ocupó veinticinco años antes en el marco, una vez más, de una guerra por el control de los recursos auspiciada por el capitalismo británico unido al incipiente capitalismo chileno. Aunque Chile (en cuyo escudo figura la leyenda 'Por la razón o la fuerza') se encastilla en el pacta sunt servanda para proclamar la intangibilidad del tratado de paz y amistad de 1904, no tuvo reparo en violar antes los tratados de límites en vigor con Bolivia. Los infractores de la ley internacional se convierten en sus adalides cuando el uso de la fuerza les permite voltearla a su favor. No obstante, el asunto actualmente pendiente ante la Corte Internacional de Justicia, consecuencia de una demanda de Bolivia, no pretende revisar el tratado de 1904 y mucho menos obtener el retorno del rico departamento marítimo del que fue despojada como consecuencia de la derrota en una guerra indeseada, sino una declaración judicial de que Chile debe cumplir el compromiso de negociar de buena fe un acceso soberano de Bolivia al océano Pacífico resultante de acuerdos y promesas generadas a lo largo de décadas independientemente de dicho tratado. Es este un tratado que Bolivia respeta, aunque obviamente, no ama, y Chile, por otro lado, no cumple en los términos autocomplacientes que expresan sus voceros ante los medios de comunicación. Bolivia nació a la independencia con mar. Su ceguera fue sobrevenida, no original. Eso hace más patético el drama. 
7. Si del aroma del mar pasamos al del desierto nos toparemos, de inmediato, con los tuareg, los hombres azules, ignorantes de las fronteras coloniales impuestas en un Sahara que sus caravanas conocen mejor que nadie. ¿Cómo no recordar que Emmeric de Vattel sostenía que el nomadismo era incompatible con la estatalidad? El Estado requiere una población sedentaria, se decía con general aprobación. Al parecer en África no bastaba. Debía ser, además, una población laboriosa capaz de poner en valor los recursos de la tierra, exigencia sine qua non para legitimar títulos de propiedad que, en otro caso, debían trasladarse a los colonos europeos de las potencias que habían 'descubierto' y ocupaban el continente. La tierra para el que la trabaja. Los tuareg han mantenido un conflicto más o menos sordo con los Estados nuevos nacidos con las hechuras de los territorios coloniales y algunos grupos tomaron la desafortunada decisión de aliarse con los islamistas más radicales armados hasta los dientes gracias a la descomposición del régimen libio de Muammar el-Gaddafi inducida por la irresponsable injerencia dizque humanitaria de los más conspicuos países europeos y de Estados Unidos, en esta ocasión con la autorización del Consejo de Seguridad (res. 1973, de 17 de marzo de 2011). Hay primaveras, como la árabe, que matan y la primavera libia desde entonces has nuestros días ha sido una fuente incesante de problemas surgidos a partir del despropósito que fue la intervención atlántica en los asuntos domésticos de Libia.

8. Es un hecho que los Estados viven en permanente transformación. Unos nacen, otros mueren o cambian, se unifican o, por el contrario, pierden las extremidades, pacífica o, más a menudo, violentamente. No menos cierto es que no hay territorio terrestre que vuelva a la condición de terra nullius susceptible de ocupación. Como ocurre con el agua del mar, de los lagos o los ríos, una soberanía siempre deja paso a otra, sin vacíos, aunque no sin litigios. 
Los problemas sucesorios están a la orden del día. La integridad territorial y el uti possidetis iuris libran una contienda dialéctica con la libre determinación de los pueblos que fueron ignorados por otros que la ejercieron en su nombre. Los acontecimientos en Crimea o en las provincias del este de Ucrania son un buen testimonio de ello.

Dentro de este proceso de transformación llaman la atención algunos hechos, escandalosos unos, polémicos otros, alguno particularmente inquietante. Un hecho escandaloso al que podría calificarse como crimen de agresión, de no estar entregada la calificación de la conducta a los agresores, es la constatación de que la destrucción del Estado ha sido el objetivo perseguido por quienes predicaban una injerencia legitimada por el afán de establecer regímenes democráticos. Yugoslavia, Iraq y más recientemente Siria pueden ser mencionados como víctimas de estas políticas llevadas a cabo por los respetables países miembros de la Alianza Atlántica, cuyas odiosas consecuencias vivimos ahora cada día.

9. Punto y aparte merece la creación del llamado Estado islámico, cocido por supervivientes de la inteligencia militar suní sobre las brasas humeantes de un Iraq arrasado de instituciones baazistas, emancipado de Al-Qaida, asentado a caballo de Siria e Iraq y con réplicas más o menos sucursalistas en Nigeria, Somalia, Libia o Malí dentro de un listado lamentablemente abierto. Si consideramos fuera de contexto los elementos de la estatalidad tendríamos que concluir que el Estado islámico es lo que pretende ser, pues cuenta con un territorio, una población y un gobierno que opera con independencia, dispone de recursos humanos y financieros, capacidad militar, de seguridad y orden público, de prestación de servicios. ¿Cómo negar que el Califato administra un territorio y a sus habitantes como cabe esperar de un Estado?

Un análisis contextual oscurece, sin embargo, la calificación. Si nos atenemos al territorio, al margen de su inestabilidad y falta 
de fronteras definidas, es un hecho que se compone de espacios sustraídos al control de los Estados a los que combate, Estados soberanos miembros de las Naciones Unidas cuya integridad territorial se recita una y otra vez en las ya numerosas resoluciones del Consejo de Seguridad que el conflicto ha venido desgranando a lo largo de los meses; en cuanto a la población, una parte parece aceptar de buen grado el Califato por su reafirmación suní y otra lo hace con resignación, pero las denuncias de violaciones sistemáticas de libertades y derechos humanos hacen dicho régimen incompatible con cualquier estándar democrático, por mínimo que sea; por último, aunque sus recursos proceden sustancialmente de la explotación y comercio del petróleo y de donaciones de adherentes y simpatizantes, se acusa a sus dirigentes de confiscar los fondos de los bancos, de extorsión, piratería y secuestro, contrabando de antigüedades, tráfico de armas y de estupefacientes. Desmantelar el comercio del petróleo y todos los tráficos ilícitos que sustentan la economía del Estado Islámico ha sido objeto de medidas y sanciones adoptadas por el Consejo de Seguridad (así, res. 2199 y 2253, de 12 de febrero y 17 de diciembre de 2015).

Para colmo, el Estado Islámico se ha erigido en actor protagonista de la injerencia terrorista más allá del territorio que directamente ocupa, en tres continentes, con una cadena de crímenes que no cesa, centenares de muertos, miles de heridos, conmoción pública, despliegue mediático, altos niveles de alerta, brotes xenófobos... De ahí que el Consejo de Seguridad (res. 2249, de 20 de noviembre de 2015), al condenar sus atentados, lo haya calificado de "amenaza mundial de una gravedad sin precedentes para la paz y seguridad internacionales", aprobando un proyecto de Francia enmendado por la Federación Rusa, en que se autoriza a los Estados miembros a ejecutar "todas las medidas necesarias" para combatirlo "conforme al Derecho Internacional y a la Carta”. Para esta fecha Estados Unidos había ejecutado ya seis mil cuatrocientas setenta y una operaciones 
y otros miembros de la "coalición contra el Estado Islámico" mil ochocientas dieciocho, dos tercios sobre Iraq y el tercio restante sobre Siria. Hay quien, como Paolo Picone ("Unilateralismo e Guerra contro l'ISIS", Rivista di Diritto Internazionale, 1/2015, pp. 5-27), propone apreciar estas operaciones, en términos de responsabilidad internacional, como una reacción colectiva frente a la violación grave de obligaciones 'erga omnes'.

Ningún Estado ha reconocido al Estado Islámico como tal y algunos -más allá de Siria e Iraq directamente implicados- lo combaten, como acabamos de señalar, militarmente. Este hecho ha reverdecido el papel del consentimiento del soberano local como condición del recurso a la fuerza por terceros en un territorio que no les pertenece, excluida la noción de legítima defensa colectiva justamente por la negación de que el atacante sea un Estado. Y aquí no han faltado las observaciones técnicas. Mientras que el consentimiento expreso de Iraq (20 de septiembre de 2014) ha legalizado los bombardeos de Estados Unidos, Francia y otros países aliados sobre suelo iraquí, las incursiones aéreas de estos mismos países sobre Siria no han contado con la autorización del gobierno de Damasco; de manera que -hostiles como han sido al régimen de Bashar al-Ásad- han tenido que buscar una cobertura legal para sus acciones en las resoluciones del Consejo de Seguridad que ya hemos mencionado. Según el gobierno iraquí (cartas de 25 de junio y 20 de septiembre de 2015) el Estado Islámico había establecido "un santuario fuera de las fronteras de Iraq" que constituía "una amenaza directa para la seguridad del pueblo y territorio iraquí". El punto es discutible en la medida en que los objetivos no han sido exclusivamente las bases y posiciones del Estado Islámico. Puede decirse que sólo la Federación Rusa ha combatido contra el Estado Islámico en Siria a petición de su gobierno. Y lo ha hecho bastante bien, a diferencia de la coalición liderada por Estados Unidos, que se empeñó en dispararse tiros al pie al tratar de luchar al mismo tiempo contra Damasco 
y Raqa, la capital del Califato. El afán por destruir al régimen de Bashar al-Ásad, alineado con Irán, ha favorecido objetivamente al Estado islámico, cuyas relaciones más o menos oficiosas con Arabia Saudí, Turquía y otros países aún han de ser esclarecidas. Por fin, un cierto entendimiento entre Estados Unidos y la Federación Rusa parece propiciar el difícil arreglo político en la guerra civil abierta en Siria hace cinco años, con exclusión del Estado Islámico y del Frente Al-Nusra y asociados de Al-Qaida, sobre los que ahora puede concentrarse la acción militar en la que en tierra las milicias kurdas desempeñan un papel más que notable. Está por ver cual será su recompensa y cómo se recompondrá el mapa político de la región configurado por Francia y el Reino Unido al desvanecerse el Imperio Otomano.

10. Los tiempos que vivimos, dada la volatilidad y fragilidad de numerosos Estados, han obligado a reconsiderar, en el orden jurídico, la relevancia del reconocimiento en el nacimiento, transformación y extinción de esos sujetos primarios y plenarios de la sociedad y el derecho internacionales. La doctrina aún parece decantarse por el carácter meramente declarativo de esta institución; el Estado existe desde que se verifica la conjunción de los tres elementos que lo definen (territorio, población y gobierno independiente), se dice. Los demás Estados, mediante el reconocimiento, constatan a discreción una realidad efectiva con sólo los límites que imponen las normas imperativas (como la que prohibe reconocer un título de soberanía derivado de la conquista) o reglas particulares convenidas de cuyo incumplimiento habría que responder ante las otras partes. Un reconocimiento de una situación que no es real o efectiva puede considerarse prematuro y, en cuanto tal, un acto de injerencia en los asuntos de otro Estado soberano.

En la práctica, sin embargo, el reconocimiento es constitutivo de la estatalidad porque de nada sirve ser Estado si no se te reconoce 
como tal. Los derechos se predican del Estado soberano reconocido. El reconocimiento obra milagros. Prestar ayuda a un movimiento separatista violento es un gravísimo acto de injerencia, una agresión; pero en cuanto el Estado injerencista lo reconoce como representante de un Estado nuevo, la intervención se transforma por arte de magia legal en legítima asistencia frente a la fuerza de quien defiende su integridad territorial. Poco importa que el reconocimiento sea prematuro en una sociedad descentralizada en que las denuncias de la ilegalidad son inoperantes frente al poder.

Obviamente, cuando un ente al que se reconoce como Estado flaquea en alguno de sus elementos naturales, sea el territorio (como Palestina o la República Árabe Saharaui Democrática) o el gobierno (como Somalia) el status derivado de la estatalidad se relativiza; pero ese mismo relativismo es consustancial con la mayor o menor amplitud del reconocimiento al margen del examen de los elementos naturales. Así la República Turca del Norte de Chipre es Estado sólo para Turquía, que ocupó ese territorio hace más de cuarenta años (en uno de los no escasos actos ilegales que ha protagonizado en la región); Taiwan o Kosovo disfrutan de círculos de reconocimiento limitados, el primero por la política de la China Popular de negar relaciones diplomáticas con los Estados que las tengan con Taiwan, el segundo por la justificada animadversión de un número considerable de Estados a aceptar a un sujeto desgajado unilateralmente de Serbia, bajo el patrocinio de Estados Unidos y conspicuos miembros de la Unión Europea. En el caso de Estados surgidos de procesos violentos de separación el reconocimiento por el Estado matriz es indispensable. Mientras no se produzca siempre podrá invocar el ejercicio legítimo de la fuerza para reprimir un movimiento secesionista, sea cual sea su asentamiento. Los límites de su acción podrán venir sólo del Derecho Internacional Humanitario y de los Derechos Humanos. En cierto modo puede decirse que un Estado se viste de largo cuando es admitido como 
miembro de las Naciones Unidas. Eso ofrece a su estatalidad una proyección universal. Es significativo que todos los sujetos estatales discutidos se mantengan fuera de la Organización.

11. Cabe preguntarse asimismo, al hilo de los acontecimientos que vivimos, si acaso cabe una retirada o suspensión del reconocimiento de Estados. El asunto tiene interés ante la perspectiva -que no es puramente hipotética- de que organizaciones terroristas, narcotraficantes o del llamado crimen organizado acaben corrompiendo a la administración y apoderándose de las instituciones de un Estado soberano y reconocido, miembro incluso de las Naciones Unidas. En realidad, no sería ésta una herramienta imprescindible para combatirlos y, desde luego, no cabría entregar su empleo a un Estado o grupo de Estados, actuando unilateralmente. La Carta de las Naciones Unidas dispone de los recursos necesarios, especialmente en su capítulo VII, para hace frente a esta amenaza. Quienes no aceptan obligaciones internacionales no pueden reivindicar derechos. A salvo -siempre es aconsejable repetirlo- los derechos de que son titulares los individuos.

12. Pero esta es una pendiente por la que pueden deslizarse situaciones en las que las calificaciones son más interesadas y vidriosas. Ya hemos señalado antes la paradoja de que mientras la condición democrática del Estado legitima su soberanía y protege su organización e independencia de toda injerencia extranjera, la acusación del carácter no democrático del Estado ha envenenado las relaciones internacionales permitiendo a las potencias ansiosas de recuperar su hegemonía o influencia allí donde la han perdido urdir planes de injerencia dizque humanitaria. Los ejes del mal, las listas negras, la calificación de este o aquel Estado como una amenaza a la paz, son del peor agüero, cuando se formulan por Estados Unidos y se jalean por sus palmeros; más aún cuando 
algunas democracias del Primer Mundo podrían ser acusadas de agresión y crímenes de guerra -y no sólo de formas más blandas, emboscadas o sutiles de intervención- en otros países. Se invaden competencias, se criminalizan decisiones soberanas, se imponen formas de cooperación a los otros, en pos de contar con gobiernos domesticados (a los que halaga la etiqueta de aliados), seguros para la conservación de un sistema del que son comisionistas.

13. Memento. El derecho de libre determinación es la dimensión comunitaria de los derechos y libertades de los ciudadanos, traduce la soberanía popular y hace realidad el Estado democrático, fortaleciendo su legitimidad. Cuando la libre determinación popular se trasunta en la soberanía el Estado soberano y democrático son uno y el mismo. No cabe la injerencia. Pero ¿y si no es así? Distintas instancias políticas y doctrinales del Primer Mundo reclaman una acción apostólica, solidaria e, incluso, coercitiva para hacer efectivo ese derecho de los pueblos, rezando el credo de la significación unívoca de la democracia, unida a su banalización, que conduce a considerar democráticos a los gobiernos amigos por el simple hecho de celebrar elecciones periódicas, y como no democráticos a los regímenes que desafían el neoliberalismo, aunque celebren esas mismas elecciones. La afirmación de que se alcanza el poder por los cauces democráticos para socavar las libertades y derechos desde las instituciones ocupadas por los movimientos revolucionarios parece de dirección única.

Cuando se habla de promover el principio democrático conviene hacer distinciones. No es lo mismo reconstruir un Estado que hasta hace poco llamábamos fallido, y los buenos modales terminológicos adjetivan ahora como frágil o vulnerable, donde se han producido grandes catástrofes naturales y humanas, como Camboya, Haití o Somalia, que imponer un cambio de régimen en un país al que simplemente se tilda de no democrático con la brocha gorda 
de sus críticos, si es que no se le acusa de estar prendido en las redes del narcotráfico y toda clase de contrabandos, actividades corruptas, blanqueo de capitales. No es lo mismo actuar mediante un esfuerzo multilateral gestionado por las Naciones Unidas que hacerlo unilateralmente, solo o en cuadrilla, invocando arteramente una justa causa. Cuando la inquietud por la democracia se asocia a una violencia generalizada y violaciones masivas y sistemáticas de derechos humanos fundamentales, esa situación marca el territorio de la injerencia humanitaria y abre la puerta al ejercicio por el Consejo de Seguridad de sus competencias conforme al Capítulo VII de la Carta. De no ser ese el caso, hay que andarse con cuidado.

Con independencia del juicio de oportunidad que merezcan, no se puede poner tachas de legalidad a acciones que se dicen inspiradas por políticas pro democracia dentro del ámbito de discrecionalidad que las normas internacionales conceden a los Estados, actuando individual o colectivamente. En este sentido, los Estados son libres para mantener relaciones diplomáticas, consulares y comerciales con quienes gusten, a salvo los tratados en que sean partes. Asimismo, pueden estimular la cultura, los procesos e instituciones democráticas o patrocinar programas para la instauración y consolidación del estado de derecho, en su caso a través de organizaciones internacionales. La presencia de éstas para supervisar procesos electorales es habitual, previa invitación del Estado en que se celebran. Igualmente, las Organizaciones internacionales pueden hacer condición de admisión y permanencia la adopción de un régimen democrático, tal como sus miembros lo entienden. Así se advierte, por ejemplo, en la Carta revisada de la Organización de Estados Americanos (artículo 9). Pero no se debe ir más allá.

14. Las cuestiones que plantea la democracia, antes incluso de ser adjetivada, son tales que conviene dejar su respuesta al pueblo soberano, sin intercesiones ajenas. La manipulación histórica de 
los principios de soberanía (no intervención) y libre determinación (democracia) por las grandes potencias responde a un juego dialéctico maniqueo y, por lo que hace al Primer Mundo, la libre elección del régimen político, económico y social tiene sus limitaciones cuando no encaja en el molde de la llamada democracia representativa y el libre mercado, ambos inextricablemente unidos. Así, la libre determinación es de menú único todos los días de la semana en cualquier lugar del planeta en que los intereses geopolíticos, estratégicos y económicos lo reclame.

Democracia representativa ¿de quién? Diríase que se han buscado aquí y allá las apariencias de la democracia formal para continuar sustancialmente con políticas contrarias a los intereses populares, incompatibles con los de las clases instaladas en las instituciones, protegidas por la legislación adecuada para permanecer en ellas indefinidamente. De esta manera, quienes combaten este estado de cosas pueden ser acusados de atentar contra el Estado democrático y la fuerza represiva puede ponerse al servicio de la democracia representativa. El registro histórico no permite ser demasiado optimista sobre lo que cabe esperar de los Estados capitalistas demo-liberales cuando se aplican a difundir sus valores. Con ellos avanzan al Sur, dispuestos a socavar las bases más profundas de la libre determinación de los pueblos con la ingeniería de formas aparentemente democráticas ocupadas por clientelas locales.

15. En definitiva, el Estado sigue siendo un concepto y una realidad indispensable en el orden internacional, pero no todos los Estados tal como los conocemos actualmente parecen serlo y algunos, incluso, aquéllos que violan las libertades y derechos fundamentales de individuos y grupos sociales, no merecen serlo. No obstante, hay que precaverse de alegatos entusiastas en pro de un nuevo orden internacional impuesto a los recalcitrantes en una sociedad mostrenca manejada por Estados o grupos de Estados más 
poderosos que auténticamente representativos de una humanidad desvertebrada. Brindemos por el Estado genuinamente democrático, pero con buen vino.

Si antes hemos mencionado que es la condición democrática del Estado la que legitima su soberanía y hace de ella un escudo frente a la injerencia extranjera, ¿cómo no esperar de las grandes potencias y alianzas que aspiran a una posición hegemónica que denuncien como no democráticos a los Estados gobernados por regímenes que desafían al establecimiento, al sistema por considerarlo dañino para los intereses de los pueblos y de los ciudadanos? En una reacción muy natural, tachados y estigmatizados como rogue States o Estados hampones, buscarán éstos sus propias alianzas y tratarán de forjar quintas columnas en los países desarrollados capitalistas entre quienes padecen las políticas neoliberales salvajes que arruinan su bienestar para engordar los beneficios de los poderes fácticos y de sus menestrales políticos. Ciertamente la noción de democracia es compleja y hoy se utiliza como arma arrojadiza en cualquier dirección. 